\title{
Ciclo de vida de los destinos turísticos y estrategias de comunicación:
}

\section{los casos de España y Chile}

Tourist Destinations' Life Cycle \& Communication Strategies: The Cases of Spain And Chile

Blanca García Henche Universidad de Alcalá Blanca.garcia@uah.es

Eva Reinares Lara Universidad Rey Juan Carlos eva.reinares@urjc.es Guillermo Armelini Universidad de los Andes garmelini.ese@uandes.cl
García, B., Reinares, E. y Armelini, G. (2013). Ciclo de vida de los destinos turísticos y estrategias de comunicación: los casos de España y Chile. Tourist Destinations'Life Cycle \& Communication Strategies: The Cases Of Spain And Chile. Revista Internacional de Investigación en Comunicación aDResearch ESIC. № 7 Vol 7. Primer semestre, enero-junio 2013. Págs. 76 a 93 DOI: 10.7263/ADR.004.01.5 
RESUMEN

\section{JEL Classification:}

M31

Palabras clave:

Ciclo de vida del destino turístico, estrategias de comunicación del destino turístico, estrategias de posicionamiento del destino turístico
El ciclo de vida del destino turístico constituye uno de los temas de mayor relevancia en los análisis de competitividad turística. Muestra la evolución de un destino en el tiempo y puede ayudar a identificar la estrategia más coherente a llevar a cabo.

El presente artículo propone aplicar el modelo de ciclo de vida del destino turístico para evaluar la situación competitiva de los destinos en distintas etapas del modelo, con el fin de analizar las estrategias comerciales que optimicen su posicionamiento. De esta forma, se ha adoptado como marco de referencia para realizar este análisis, la Teoría del Ciclo de Vida de los Destinos Turísticos enunciada en 1980 por Richard Butler, y a partir de la utilización del estudio del caso como herramienta metodológica, se va a analizar el uso de los instrumentos de promoción en distintas fases del ciclo de vida del destino.

Dado el actual escenario de los destinos turísticos maduros, se ha aplicado dicho método en los casos de España (destino en fase de estancamiento) y Chile (destino en las primeras fases de desarrollo como destino turístico) para hacer un diagnóstico de la situación.

Se aspira, por lo tanto, a proporcionar una mejor comprensión del ciclo de vida de los destinos turísticos, teniendo en cuenta que el modelo de Butler es una herramienta de diagnóstico y no de decisión, y su aplicación en este análisis tiene un carácter exploratorio.

\section{ABSTRACT}

\section{Clasificación JEL: M31}

\section{Key words:}

Tourist destination life cycle, tourist destination communication strategies, tourist destination positioning strategies.
A tourist destination's life cycle constitutes one of the most relevant themes in the analysis of tourism competitiveness. It shows the evolution of a destination over time and can identify the most coherent strategy to follow.

This article proposes to apply the tourist destination life cycle model to evaluate the competitive situation of the destinations at different stages in the model, in order to analyse the business strategies that optimise their positioning. Thus in order to carry out this analysis, Richard Butler's 1980 theory on Tourist Destinations' Life Cycles is the reference framework that will be used, and the use of promotional tools at different stages in the destination's life cycle will be analysed using the case study as a methodological tool.

Given the current situation of established tourist destinations, the afore-mentioned method has been applied in the Spanish (destination in phase of stagnation) and Chilean cases (destination in the early development phase as a tourist destination) to make a diagnosis of the situation.

It is therefore hoped to offer a better understanding of tourist destinations' life cycles, taking into account that the Butler model is a diagnostic and not a decision-making tool, and its application in this analysis is of an exploratory manner. 


\section{Introducción}

La literatura académica sobre marketing estratégico en los destinos turísticos tiene un carácter fundamentalmente descriptivo de los procesos para formular e implantar estrategias en los mismos. Sin embargo, los estudios de carácter exploratorio para identificar las estrategias competitivas han tenido un menor desarrollo.

El ciclo de vida del destino turístico (CVDT) constituye uno de los temas de mayor relevancia en los análisis de competitividad turística. Muestra la evolución de un destino en el tiempo $y$, aunque con ciertas limitaciones, puede ayudar a identificar la estrategia más coherente a llevar a cabo.

En este contexto, el motivo principal para la elaboración del presente artículo, si bien a priori plantea proporcionar una descripción detallada sobre la fase del ciclo de vida en la que se encuentran dos destinos turísticos diferentes, es, a través de ella, identificar las acciones estratégicas de comunicación llevadas a cabo por dichos destinos para optimizar su posicionamiento.

En último término, se aspira a proporcionar una mejor comprensión del ciclo de vida de los destinos turísticos, teniendo en cuenta que el modelo aplicado es una herramienta de diagnóstico y no una herramienta de decisión.

La metodológica de investigación se ha basado en el estudio del caso. Siguiendo la propuesta de Stake (1994) para la investigación de los estudios de caso, se ha desarrollado un estudio instrumental y colectivo, en el que a partir del examen de casos específicos se plantea aplicar la Teoría del Ciclo de Vida del Destino Turístico propuesta por Butler en 1980, para analizar las estrategias comerciales de los destinos en distintas etapas del modelo, con el fin de obtener ideas y matizar la teoría acerca del posicionamiento del destino turístico.

Respecto al propósito de la aplicación de esta metodología, la presente investigación tiene un planteamiento descriptivo a la vez que exploratorio (Chetty, 1996), ya que por una parte se pretende identificar y describir los distintos factores que influyen en el ciclo de vida de los destinos turísticos analizados y, por otra, de acuerdo con Maxwel (1989) y Sarabia (1999), se trata de realizar un acercamiento entre el marco teórico de contexto y la realidad objeto de estudio.

Para ello, la investigación se basará en el estudio de un fenómeno contemporáneo en un entorno real, se utilizarán distintas fuentes de datos y se estudiarán en lugar de un caso único, dos casos (Yin, 1994), dos destinos turísticos en fases de su ciclo de vida muy distintos: España y Chile. Se considera que un estudio instrumental de dos casos permite un cierto grado de aplicabilidad general de las conclusiones obtenidas, en la medida en que los destinos analizados se encuentran en fases muy diferenciadas en su ciclo de vida. Por otra parte, el utilizar dos casos de estudio tan dispares permitirá obtener un conocimiento más amplio sobre el fenómeno (Chetty, 1996). Se han elegido estos dos países de forma deliberada porque se revelan críticos para entender y valorar una teoría ya existente; aunque la mayoría de los estudios están realizados en torno al producto-destino y en el presente estudio el centro de atención será el uso de los instrumentos de comunicación ante las distintas fases del ciclo de vida de destino en la que se encuentran ambos países. La representatividad del estudio reside en las cualidades metodológicas de los casos elegidos, a la vista de los resultados que ofrece su análisis. Por ello se ofrece su observación de la fase del ciclo de vida del destino en la que se encuentran España y Chile, tra- 
tando de comprender el proceso por el cual tienen lugar ciertas decisiones y fenómenos, concretamente la utilización de los instrumentos de comunicación según la fase del ciclo de vida del destino en cada caso.

A continuación, adaptando las propuestas de Yin (1994) para estudios de caso, a partir de la especificación de las unidades de análisis, se realizará una proposición teórica sobre el ciclo de vida de los destinos turísticos objeto de estudio y las estrategias de comunicación en sus etapas, para posteriormente vincular los datos a las proposiciones plateadas.

\section{Ciclo de vida de los destinos turísticos}

La utilización del concepto de "Ciclo de Vida del Producto" es bastante reciente en el sector turístico y se ha aplicado especialmente a los destinos turísticos (Serra, 2000). El ciclo de vida del destino turístico constituye uno de los temas de mayor relevancia en los análisis de competitividad turística.

El modelo propuesto por Butler en 1980 representa uno de los paradigmas esenciales en torno al desarrollo de los destinos turísticos (Lundtorp y Whanhill, 2001) y es uno de los enfoques de mayor influencia y más ampliamente referenciado en el análisis del desarrollo del turismo local (Harrison, 1995). Previamente, autores como Gilbert (1939) y Christaller (1964) ya identificaron tres estadios en el progreso de los destinos turísticos en los que se detectaban ciertas regularidades en su crecimiento. Noronha (1976), Miossec (1977) o Stanfield (1978) basan también sus aportaciones en la idea fundamental de que los destinos trascurren por una serie de fases o ciclos a lo largo de su vida.
El modelo de CVDT de Butler se fundamenta en la Teoría del Ciclo de Vida del producto propuesta por Dean en el ámbito de gestión del Marketing (1950), adaptándola a los destinos turísticos como si de un producto se tratase, y teniendo en cuenta dimensiones relacionadas con las infraestructuras, actitudes de los turistas y residentes, implicación de agentes locales y externos en la comercialización del producto, accesibilidad a los destinos y competencia de los mismos.

Según los estudios de Butler (1980), las fases que atraviesa un destino son: exploración, implicación, desarrollo, consolidación, estancamiento y declive. Cada etapa presenta una serie de rasgos característicos en cuanto a la situación de la demanda, la oferta, la comercialización y la competencia.

Todo ciclo comienza en la fase de exploración, en la que se descubre el destino y es visitado por un número reducido de personas que huyen de los viajes masivos. En esta etapa los destinos son poco accesibles y sin instalaciones turísticas.

En la fase de implicación el número de turistas crece como resultado de los nuevos equipamientos creados por parte de iniciativas locales. El destino se hace más popular, se va desarrollando mercado y una temporada turística. En esta fase se demanda de la Administración pública una mayor implicación en el proyecto, principalmente a nivel de infraestructuras.

En la fase de desarrollo la llegada de turistas es mucho mayor, el control de la actividad turística lo ejercen compañías externas, ya no locales, modernizando instalaciones, invirtiendo en hotelería de marcas de referencia e incorporando tour operadores. La singularidad del destino comienza a perderse debido a la masificación y se identifica un sector público más involucrado. 
En la fase de consolidación el número de turistas crece pero no de forma tan exponencial como en la fase anterior. El destino ya forma parte de la industria organizada. Los niveles de venta elevados hacen posible obtener economías de escala y, por ello, altos beneficios. Los turistas iniciales se han desplazado a otros destinos.

La fase de estancamiento supone que el número de turistas no crece y el destino comienza a perder su atractivo. Existen muchas compras de repetición y en muchos casos la capacidad de acogida puede haberse sobrepasado.

En la fase de declive se produce una pérdida de visitantes que se trasladan a nuevos destinos. El destino comienza a reducir precios para captar clientes y mantener la cuota de mercado. Es en esta fase cuando se toman medidas para rejuvenecer el destino, buscando nuevos usos, nuevos clientes, nuevos canales de distribución y diseñando nuevos productos con el fin de reposicionar el destino.

La teoría del ciclo de vida del producto requiere adaptaciones para su aplicación en el contexto turístico. De la misma manera, implica una serie de limitaciones como herramienta para la dirección estratégica y es preciso considerarla como una herramienta de diagnóstico del progreso del destino y no como una herramienta de decisión.

Tal y como señala Camisón (1998), la explicación del desarrollo de los destinos turísticos proporcionada por el ciclo de vida, puede emplearse como criterio para la valoración de las diferentes opciones estratégicas, con el fin de aprovechar las oportunidades que en cada caso presenta el mercado, sin embargo no proporciona pautas de actuación. Lo que si es evidente es que la fase del ciclo de vida del destino turístico condicionará las estrategias comerciales a utilizar en cada caso.
Una de las aportaciones más interesantes del modelo de Butler, es que el conocimiento de la senda de evolución del destino y los factores que la han generado, puede ser una información muy valiosa a tener en cuenta en el proceso de dirección estratégica de los destinos (Martín Azami, 2004). La importancia del modelo radica en su contribución en el diagnóstico del progreso del destino. No obstante, diversos autores como Foster y Murphy (1991), plantean que, a pesar de la aplicabilidad del modelo, es necesario hacerle algunas revisiones teniendo en cuenta la demografía y condiciones del mercado de cada región.

El modelo resulta útil como marco descriptivo de referencia, pero se pueden producir desviaciones como consecuencia de la heterogeneidad del mercado y de la naturaleza propia del destino turístico como amalgama de actividades muy diversas (Berry, 2001; Lundtorp y Wanhill, 2001), aspectos que no tiene en cuenta el modelo. El modelo supone una descripción simplificada de algunos procesos reales (Aguiló et al., 2002). Es útil para evaluar el alcance por el que un fenómeno social específico, confirma o se desvía de un reconocido estándar. En este sentido, el CVDT permite medir y valorar las desviaciones de la realidad de los diferentes destinos (Martín Azami, 2004).

Si en vez de hacer referencia al producto o destino se hace al sector turístico, se puede afirmar que la etapa del ciclo de vida del sector condiciona la información de los operadores que lo forman, así como la manera en la que la información se utiliza para realizar estrategias que posicionen a las empresas con una ventaja competitiva sobre sus rivales.

El sector turístico a nivel global se encuentra en una fase de crecimiento, según muestran los 
informes de la Organización Mundial de Turismo; pero la situación por países y productos es muy dispar. La evolución del turismo ha sido muy rápida, lo que ha provocado la necesidad de una adaptación constante de los destinos a nuevas situaciones del mercado, los nuevos gustos, las nuevas necesidades de los consumidores turísticos, etc.

Partiendo de que los destinos turísticos son dinámicos y evolucionan en el tiempo, esa evolución o cambio puede ser debida a cambios en los consumidores turísticos (Cohen, 1972; Plog, 1974) o en el propio destino (Christaller, 1964). Ante esa evolución, las empresas y destinos turísticos utilizaran de distinto modo y con distinta intensidad los instrumentos comerciales. Así, es evidente que las acciones de marketing han de adaptarse a la situación o fase del ciclo de vida en que se encuentren los destinos.

La evolución condiciona el desarrollo de nuevos productos y la estrategia comercial a seguir. Las estrategias de comunicación, por ello, serán muy diferentes cuando la finalidad de las mismas sea dar a conocer un destino turístico, en las primeras fases del ciclo, que en las fases de consolidación o estancamiento, donde la comunicación estará basada en la imagen de diversificación del producto.

\section{Aplicación del modelo de ciclo de vida del destino: los caso de España y Chile}

De acuerdo con los parámetros propuestos en el análisis de las etapas del ciclo de vida de cada destino: número de visitantes, evolución de la demanda, características de la oferta, campañas de comunicación y estudio de la competencia, podemos afirmar que España es un destino que se encuentra en fase de estancamiento, al igual que su producto principal, el turismo de sol y playa. Como otros destinos tradicionales, España se enfrenta al reto de mantener su atractivo para el mercado. Según el informe anual de Frontur (Instituto de Estudios Turísticos, 2010), el $65 \%$ de los turistas viene a este destino buscando el sol y la playa, pero se están vendiendo ya productos complementarios que permiten añadir visitantes y, sobre todo, ingresos. En 2010 España recibió 250.000 turistas extranjeros atraídos por la gastronomía y el turismo rural, y las cifras están evolucionando al alza. El turismo urbano también es otra apuesta por parte de Turespaña, por ejemplo en el año 2010 Madrid recibió un $9.8 \%$ más de turistas que el año 2009 y casi el doble que en 2003.

Chile, por el contrario, es un destino en las primeras fases del ciclo de vida como destino. Según la modelización propuesta por Butler (1980) se encuentra entre las fases de implicación y de desarrollo a nivel país, y en la fase de implicación en muchas zonas turísticas. Los productos que comercializa, turismo de naturaleza y turismo cultural, se encuentran en fase de desarrollo.

\subsection{Caso España}

El turismo es en España una de las actividades más importantes en la economía del país. El desarrollo y crecimiento español no se puede entender sin tener en cuenta el papel que ha jugado el turismo. Sin embargo ha estado demasiados años fundamentado sólo en explotar el turismo de sol y playa, con un significativo crecimiento desde los años setenta, mientras que en los últimos años está mostrando síntomas de agotamiento (Vera y Montfort, 1994).

Estos últimos años el turismo ha sufrido notables cambios, el turista no desea sólo sol y pla- 
ya, sino que se centra más en la búsqueda de la experiencia, lo que se denomina "cultura turística". Ha pasado de ser un simple turista a ser un consumidor turístico (Ejarque Bernet, 2005), y en la actualidad el sector está experimentando profundos cambios en los gustos y deseos de los consumidores, que se hacen cada vez más exigentes con la calidad y las condiciones (comerciales y medioambientales) de los productos turísticos que se ofrecen (García Henche et al., 2010).

Ante esta situación se plantea el estudio de indicadores del ciclo de vida del destino España, para conocer la fase en la que se encuentra el mismo.

El primer indicador utilizado en el análisis el ciclo de vida de un destino es el número de visitantes y la evolución de la demanda. En los destinos en estancamiento el número de turistas alcanza su máximo, lo que lleva a exceder la ca- pacidad de los factores relevantes, acarreando problemas económicos, sociales y medioambientales.

Durante el año 2009 visitaron España un total de 52,2 millones de turistas internacionales (Instituto de Estudios Turísticos, 2010), cifra que resultó un 8,7\% inferior a la registrada en 2008. Esto se ha traducido en aproximadamente 5 millones de turistas menos. Se trata del segundo año consecutivo en el que la serie de llegadas recogidas en el informe Frontur presenta un retroceso, aunque en este caso ha sido más intenso que el registrado en 2008 (-2,5\%), lo que ha supuesto volver a los niveles alcanzados en el año 2004.

Esta evolución ha sido la continuación de la desaceleración sufrida desde el año 2006 en el ritmo de crecimiento de las llegadas internacionales, que culminó en el mencionado descenso del año 2008. (véase gráfico 1).

\section{Gráfico 1 • Llegadas de turistas internacionales a España.}

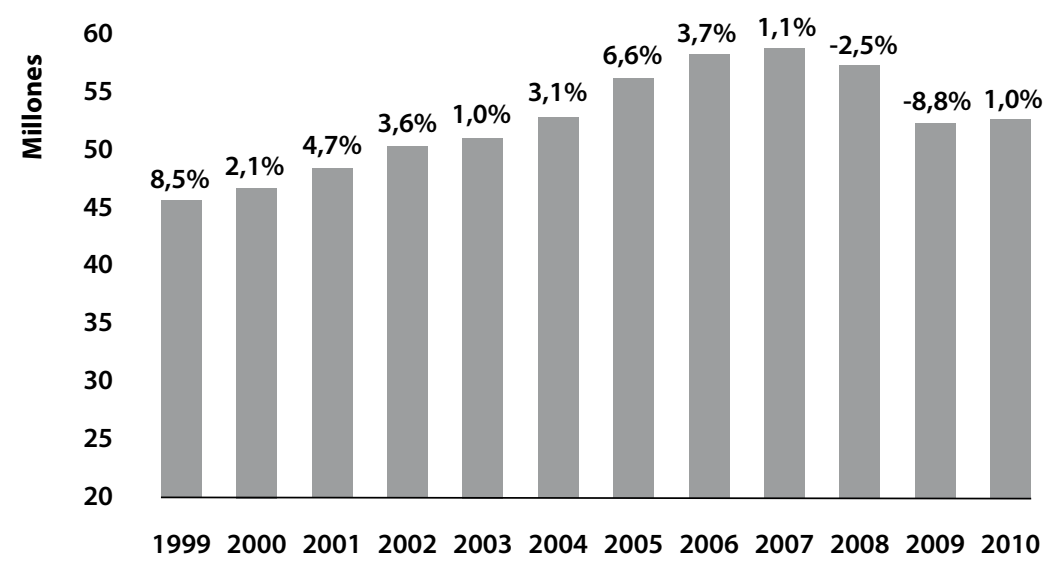

Fuente: Instituto de Estudios Turísticos (2010) 
El segundo indicador utilizado en el estudio del Ciclo de vida del destino España es la competencia en el mercado. Cada vez hay más países que suponen una competencia para España, ofreciendo precios más competitivos y el valor añadido de ser destinos nuevos sin explotar y con culturas distintas, como Túnez, Turquía o Croacia.

Tradicionalmente factores como el precio y la especialización eran valores bastante seguros para el éxito de España como destino turístico. Actualmente aunque son necesarios, ya no está tan claro que sean suficientes para realmente ser un destino competitivo.

Los siguientes indicadores hacen referencia a la comercialización de la oferta turística. Los destinos que se encuentran en las fases finales del CVDT han de realizar acciones de comercialización para conseguir el mantenimiento de su demanda y la revitalización de la oferta. La fase de madurez se caracteriza principalmente, por la saturación de la demanda del producto tradicionalmente ofertado -Ej., sol y playa — , bajo grado de diferenciación de los productos, aparición de destinos sustitutivos, infraestructuras obsoletas y una masificación del espacio con un consiguiente desgaste del medio (Vera y Montfort, 1994; Oreja y Montero, 1997; Knowles y Curtis, 1999).

Exceltur (2011) manifiesta que se debe modificar el modelo del sector turístico español, el cual se encuentra estancado desde los años 90. Así, estima que es necesario realizar propuestas integrales que refuercen estrategias de reposicionamiento que sean sostenibles a largo plazo.

Como se ha señalado, estos indicadores confirman que España es un destino que se encuentra en fase de estancamiento. La clave del éxito español será asimilar esta gran transformación y marcarse como meta la humanización del servicio, la conservación de los espacios naturales, y el diseño de nuevos servicios. A su vez es necesario modernizar nuestros productos turísticos, mejorar la calidad, y diversificar nuestra oferta turística tradicional, buscando alternativas que permitan atender a un mercado cada vez más segmentado.

Para la consecución de dichos objetivos, la Secretaría de Turismo y Comercio, ha fijado tres frentes de actuación, diferenciando entre aquellas líneas de carácter estratégico, tendentes a adaptar la estructura del sector a los cambios de la demanda, las líneas de actuación por mercados, que buscan optimizar las estrategias dirigidas a los diferentes mercados emisores, particularmente en aquellos que presentan estancamiento o recesión, y las líneas de actuación por productos para potenciar las diferentes formas de oferta turística en el sector (García Henche et al., 2010). Dentro de los nuevos objetivos establecidos de Turespaña se puede destacar:

- Investigación de mercados.

- Imagen de marca y comunicación.

- Desarrollo de producto y comercialización.

- Marketing online.

- Excelencia en la gestión.

Para ello cuenta con un plan estratégico, denominado "Plan de Objetivos de Promoción Exterior del Turismo" (Turespaña, 2006), cuyo esfuerzo promocional se ha dirigido especialmente al impulso del turismo cultural y de ciudad.

Por otra parte, la Secretaria General de Turismo (2008), en su "Plan de Turismo Español Horizonte 2020", se propone la amplitud de nuevas líneas de productos turísticos basados en la individualización, introduciendo valores emocionales y con una mayor personalización para el tu- 
rista, con el objeto de crear productos innovadores, que constituyan experiencias únicas, diferentes de los productos estandarizados y permitan mejorar el posicionamiento competitivo de España.

El Gobierno presentó en marzo de 2010 una nueva, campaña de promoción internacional de Espana, bajo el lema "I need Spain", manteniendo como logotipo el Sol de Miró, que Turespaña utiliza desde hace 25 años. La iniciativa ha supuesto una inversión de 7,5 millones de euros en su desarrollo, más 42 millones anuales en inserciones publicitarias. Se pretende consolidar el "liderazgo español" en el turismo vacacional y diversificar la demanda turística. La campaña publicitaria, llevada a cabo por el Instituto de Turismo de España, tiene como objetivo promocionar el mercado turístico español para los extranjeros, por ello en sus anuncios no sólo tratan de vender España como destino, sino de resaltar la hospitalidad y el estilo de vida, con lo que se pretende aumentar la diferenciación con respecto a otros posibles destinos competidores.

La campaña se ha proyectado en más de 40 países, con un público objetivo de 400 millones de ciudadanos. Se quiere llegar a todas las regiones del mundo, incidiendo en aquellas donde la imagen de España es más débil, como China, India, Oriente Próximo o EE UU. Así, por primera vez se incluyen anuncios destinados al mercado asiático o al afroamericano. Se ha realizado un importante esfuerzo para adaptar sus piezas publicitarias a las características particulares de cada mercado emisor.

Está diseñada para todos los soportes y cuenta con cuatro spots (en seis idiomas) que están siendo emitidos en cadenas de televisión internacionales, 50 visuales (en 15 idiomas), cuñas de radio y la elaboración de la imagen gráfica que se incluirá en las acciones de red de oficinas de Turespaña en el exterior.

Los spots están dirigidos a: el público familiar, los jóvenes, los turistas 'senior' y el mercado asiático, además se ha rodado un video genérico de un minuto que resume sus experiencias. La campaña presenta el estilo de vida del español, no tanto nuestros monumentos, sino las emociones. Por eso muestra a personas disfrutando en situaciones accesibles y guardan un equilibrio entre las aspiraciones del destino y los turistas que nos visitan, en su mayor parte de clase media (véase figura 1 pág. 85). En esta campaña se percibe claramente que al ser España un destino en estancamiento, la comunicación no se va a basar en los recursos sino en la diversidad de la oferta y en otros valores del servicio como la hospitalidad o la forma de vida o las experiencias que los turistas pueden tener en el destino.

El lanzamiento de la nueva imagen comenzó con una campaña en las principales cadenas de televisión de distribución mundial (CNN, FOX, National Geographic, Eurosport coincidiendo con el Mundial de Fútbol) y al mismo tiempo se lanzará la campaña online, para alcanzar notoriedad.

\subsection{Caso Chile}

Chile es un destino turístico que se encuentra en las primeras fases del ciclo de vida. En la fase de exploración un número reducido de turistas visitan el destino al verse atraídos por los recursos naturales o las características culturales del mismo, que hace que busquen un contacto con los residentes con el fin de conocer sus costumbres. El volumen de visitas es restringido por la falta de servicios turísticos - alojamientos, accesos, etc. Y en muchas zonas de Chile esta es la situación que se reconoce. 
Figura 1 • Imágenes de la Campaña “I need Spain” (2010).
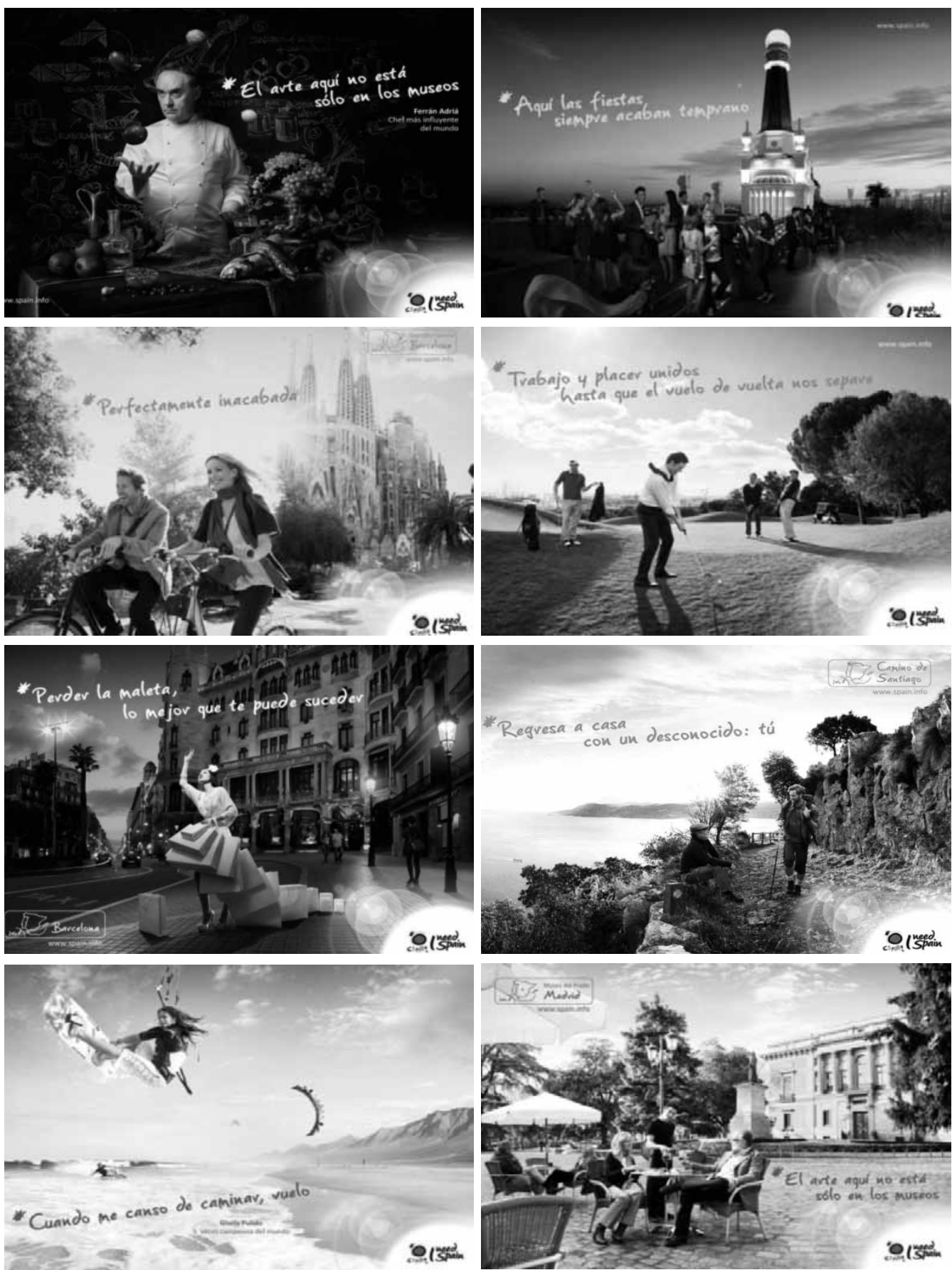
En otras zonas como Patagonia o Santiago de Chile se está produciendo una creciente llegada de turistas, incrementando la importancia del turismo como actividad económica. Las iniciativas locales comienzan a ofrecer servicios especializados a los turistas e información del destino que repercute en un incremento y un número regular en el volumen de visitas.

El primer indicador a analizar es el número de visitantes y la evolución de esa demanda. El sector turístico en Chile se compone de un 71\% de consumo interno, un 14\% de turismo emisor, y el restante 15\% corresponde al turismo receptor. Su estabilidad institucional y política ha hecho de Chile un país apto y seguro para el turismo. Es el país de América Latina con mejores indicadores económicos en términos de competitividad, apertura de la economía, estabilidad institucional para la inversión y nivel de corrupción. Cuenta con infraestructura vial muy moderna y bien comunicada, servicios aeroportuarios óptimos, y un sistema de información muy desarrollado en comparación con sus vecinos de América del Sur.

Sin embargo, el turismo no es de las actividades económicas más relevante en Chile. Durante la última década, este sector contribuyó con 3 a 4 puntos al producto interno bruto del país, mientras que en el mundo esta tasa ha sido del 8 al 9\% de promedio. Diversos factores explican esta realidad; En primer lugar destaca la ubicación geográfica. Los países de América del Sur con mayor turismo receptor (Brasil y Argentina) han recibido históricamente menos de cinco millones de turistas por año cada uno. Así la lejanía y las características del continente actúan como un factor disuasorio. En segundo lugar Chile no ha tenido históricamente una ciudad de renombre mundial como Río de Janeiro o San Pablo en
Brasil, o Buenos Aires en Argentina. Sólo en los últimos años, Santiago comenzó a posicionarse como un centro de convenciones y eventos internacionales. Finalmente, es difícil asociar a Chile con algún lugar, una personalidad, o un tema cultural muy específico (como la Samba y las playas brasileñas, la cultura Inca y el Machu Pichu Peruano, el tango y la Patagonia Argentina).

El número de turistas extranjeros que han visitado Chile durante el año 2009 fue de 2.759.000 personas (frente a los 52.2 millones de turistas recibidos por España), que han generado un ingreso en el año 2009 de 1.978 millones de dólares. Comparando las dos cifras anteriores, el gasto promedio por turista en este país durante el 2009 fue de 716 dólares, cifra que se sitúa por encima del gasto medio en países como México, pero muy por debajo de otros destinos turísticos como Brasil, Australia, Nueva Zelanda y Grecia entre otros (WTO, 2009). Como se observa en el Gráfico 2, la tasa de crecimiento de la llegada de turistas extranjeros ha sido relativamente baja, con una variación promedio anual en la serie 2001-2009 del 5\% de crecimiento. En relación a la población chilena, el turismo extranjero representa un 16\% del total de habitantes del país, cifra muy lejana a los principales receptores de turistas a nivel mundial como Francia y España (véase gráfico 2 pág. 87).

El segundo indicador a analizar en el estudio del Ciclo de vida de Chile es la competencia en el mercado. Países como Argentina, Brasil y Bolivia son sus principales competidores, esencialmente Argentina, ya que ofrece productos similares, especialmente la zona de Patagonia, y con un mayor posicionamiento en el mercado y una fuerte presencia en los canales de distribución.

Respecto a la comercialización de la oferta turística, al igual que en otros países, el turismo 


\section{Gráfico 2 - Evolución del número de turistas extranjeros que han arribado a Chile entre 2000 y 2010.}

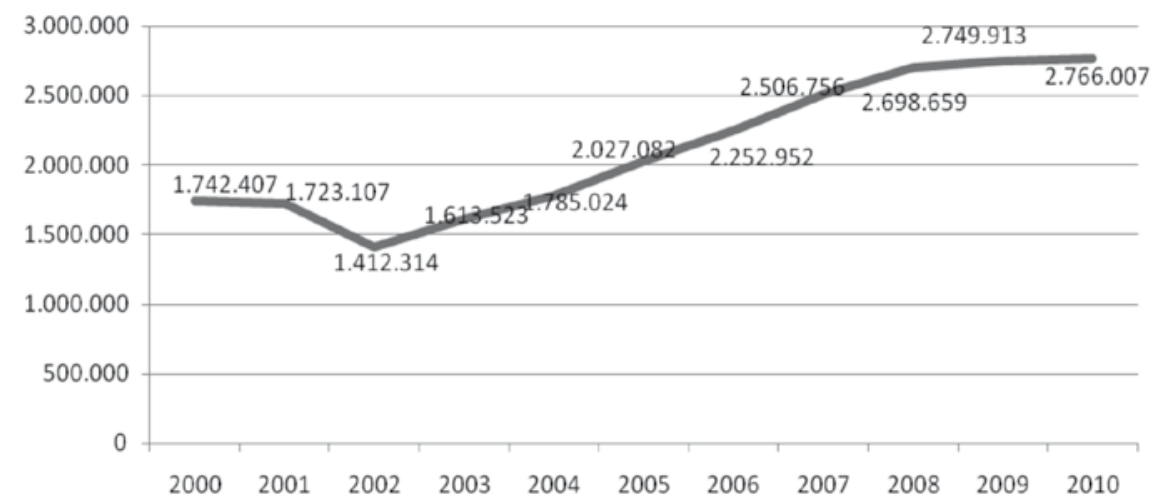

receptivo y emisor es controlado por tour operadores, agencias de viajes y líneas aéreas. En Chile, LAN (antiguamente la Línea Aérea Nacional y en la actualidad la más importante de Latinoamérica por su fusión con TAM) juega un papel muy importante. La calidad de servicio de esta aerolínea y el hecho de utilizar a Santiago como puerta de salida de países vecinos del sur (Argentina, Paraguay, Bolivia y Uruguay) hacia el hemisferio norte, ha incrementado el flujo de turistas hacia Chile.

En el sector de agencias de turismo se observa una concentración importante; sólo diez concentran el 60\% del mercado de pasajes aéreos. Este ratio es muy distinto al de países vecinos como Argentina y Perú, donde se observa un mercado muy atomizado. En este contexto, es útil destacar el papel creciente de grupos de establecimientos minoristas como Falabella y $\mathrm{Pa}$ ris de Cencosud, que utilizan su poder "multi- tiendas" para ganar presencia en este mercado. Además, la presencia regional de estas tiendas minoristas (en Perú, Argentina, Brasil, Colombia, etc.) podría potenciar el efecto de comunicación turística de Chile en la región.

Respecto a la promoción, el turismo en Chile se desarrolla a través de iniciativas públicas y privadas. Entre las primeras destaca la participación del Servicio Nacional de Turismo (SERNATUR), cuya misión es fomentar el desarrollo sustentable de la actividad turística a través de la coordinación del sector público y del sector privado. Sus iniciativas van desde la creación de paquetes turísticos conjuntamente con tour operadores y líneas aéreas, hasta el desarrollo de procesos formativos para capacitar a agentes del sector en el negocio turístico.

En el año 2005 el gobierno nacional, en alianza con diversas asociaciones empresariales, desarrolló el proyecto de marca país "Chile allways 
surprise". El concepto surgió de un estudio hecho por la consultora Interbrand, en el cual se detectó que la capacidad de sorprender se relaciona con las sensaciones, emociones y sentimientos que generan los atributos de Chile: geografía sobrecogedora, gente cálida, variada, eficiente y emprendedora, un país estable, abierto al mundo, con instituciones que funcionan. Por tanto, para el extranjero este factor sorpresa se traduce en un país más desarrollado de lo esperado, con naturaleza y geografía impactante y con gente trabajadora y emprendedora, donde las cosas funcionan. Este proyecto tuvo un presupuesto de 25 millones de dólares. El resultado de la campaña ha sido regular. Por un lado, un estudio llevado a cabo en el 2006 por MV2 Group en varios países reportó que los objetivos básicos de la campaña de asociar Chile con los conceptos descritos en el posicionamiento de marca habían sido cumplidos. Sin embargo, el elemento "sorpresa" utilizado como punto diferenciador y disparador de la imagen de marca, presentaba para varios socios del proyecto marca país, connotaciones adversas.

A partir de este criterio, el nuevo posicionamiento se ha planteado bajo un nuevo slogan, "Chile hace bien", que se sustentó en la repercusión mediática que tuvo el dramático y exitoso rescate de los 33 mineros atrapados en una mina de Copiapó el cinco de noviembre del 2010. Se estima que durante el momento del rescate la repercusión mediática alcanzó una cobertura equivalente a una inversión publicitaria de unos 2.000 millones de dólares. Este hecho se intentó capitalizar desde el gobierno para posicionar el nuevo lema en el exterior (véase figura 2).

Teniendo en cuenta los datos presentados anteriormente, se observa un estancamiento en la fase del crecimiento en los sectores de la Patago- nia, sol y playas, y en visitas al desierto. La pregunta es si este es el techo o es un estadio intermedio que se ha mantenido constante por factores que impiden su crecimiento. Probablemente la respuesta correcta sea una combinación de estas dos alternativas. Por un lado existe el factor localización geográfica, que naturalmente limita el número de turistas que pueden llegar a un sitio específico. Si se tiene en cuenta que Chile se rodea de países con relativamente poca población, y en vías de desarrollo, no es esperable un cambio radical en el número de turistas a recibir tanto en el corto como en el largo plazo. Por ello definir el ciclo de vida implica entender el potencial del mercado, y evidentemente no es esperable que Chile tenga un objetivo de un turista extranjero por habitante como tienen Francia o España por ejemplo.

\section{Figura 2 - Imágenes de la Campaña "Chile hace bien" (2010).}

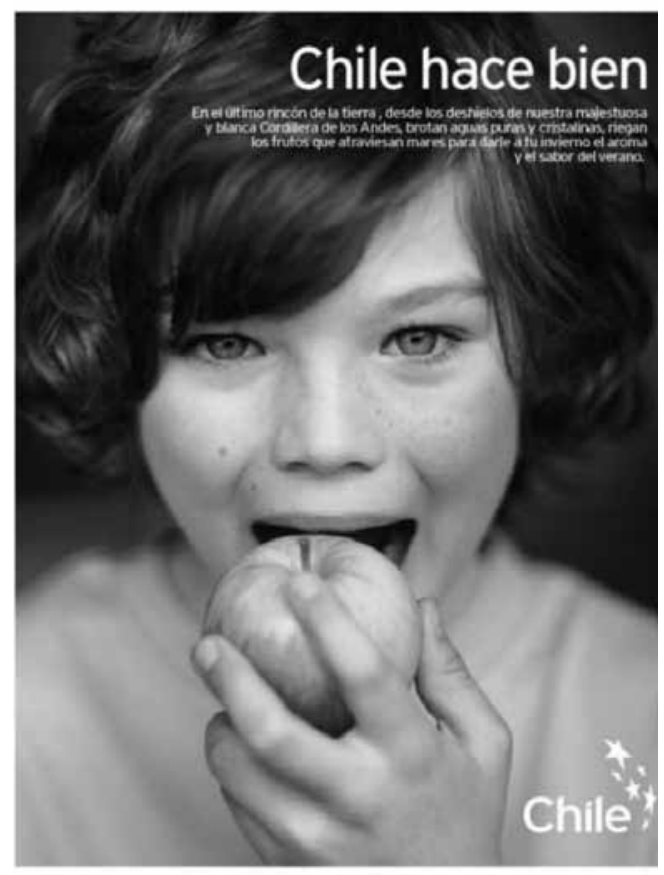




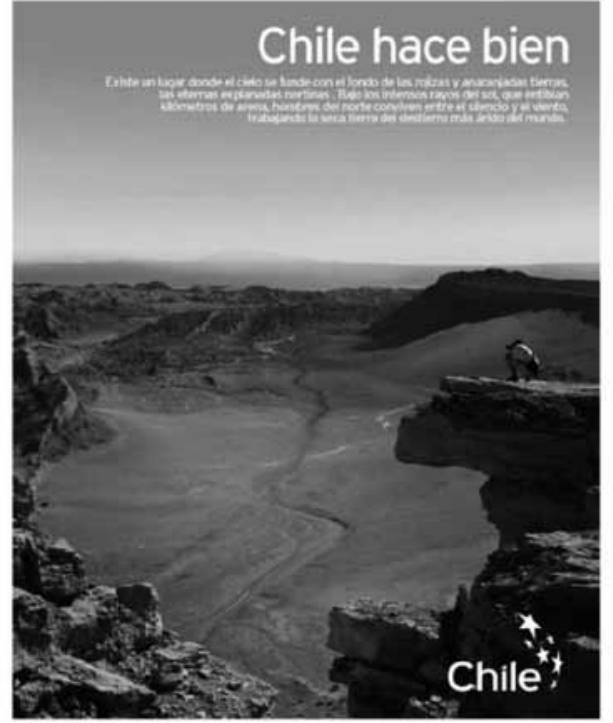

Fuente: www.senatur.cl.

Por otra parte, no ha habido una política de comunicación consistente, y un buen posicionamiento de Chile por parte del sector público y privado del país. Esta carencia agrava aún más el problema porque Chile, como se ha señalado, carece de una identidad propia a nivel mundial que lo identifique inequívocamente con un paisaje, una figura o una cultura. Si bien las comparaciones siempre tienen sus limitaciones, según un estudio de la OCDE, países con características más o menos similares a Chile, al menos en cuanto a la oferta turística, tienen un gasto per cápita considerablemente superior: Australia, primero recaudó USD4.440 por turista, 7 veces más que Chile. Nueva Zelanda, tercero en la lista, recaudó USD2.033 por turista, tres veces y media de lo que gasta un viajero en Chile. Ambos países han invertido diez y tres veces respectivamente lo que invierte Chile en publicidad, siendo además el retorno por dólar invertido también superior.

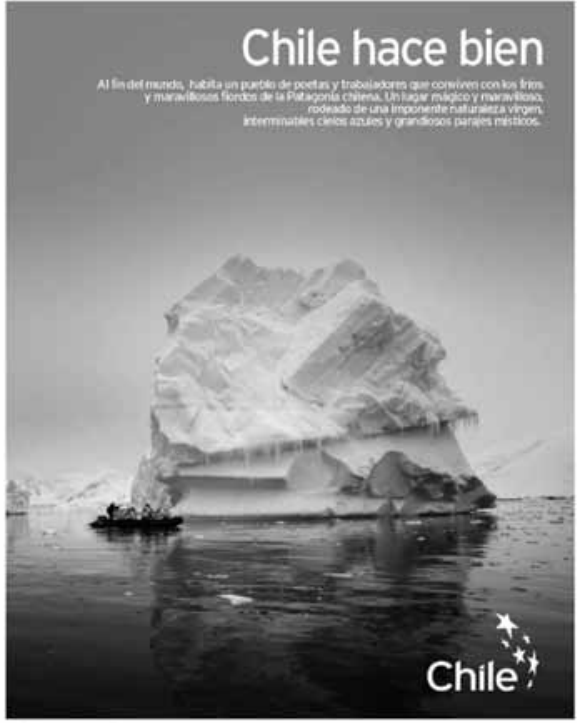

10
Santiago como destino turístico (city marketing) presenta un panorama algo distinto. Las inversiones en infraestructura en la capital chilena, el buen clima para la inversión empresarial y la creciente oferta de establecimientos para alojamiento, permiten vislumbrar un futuro promisorio para Santiago como centro de convenciones y congresos a pesar de que enfrenta una competencia importante de Buenos Aires, San Pablo y Río de Janeiro. Así se podría decir que el turismo de negocios se encuentra en la fase ascendente del ciclo.

\section{Conclusiones}

El presente trabajo toma como punto de partida el estudio de dos destinos turísticos y la implementación de las campañas de comunicación diferenciada en función de las fases del ciclo de vida de destino en la que se encuentran los mismos.

El instrumento comunicación resulta un factor clave para los destinos turísticos. Imagen, 
comunicación, marketing on line y comercialización son, ante todo, estrategias basadas en dicho instrumento. Las etapas del ciclo de vida en la que se encuentren los destinos demuestran un uso diferenciado de los instrumentos de comunicación, desde un país en las primeras fases a otro que se encuentra en las últimas fases del ciclo de vida como destino turístico.

Las principales conclusiones que se pueden extraer de este análisis, referidas a los dos casos de estudio, España como destino en estancamiento ha de crear más estatus promocionando atributos únicos que posee: su cocina, cultura, paisaje, las ciudades y pueblos españoles etc. No es que haya que cambiar lo que existe, sino que habría que presentar una estrategia planificada, con el fin de perfilar imágenes alternativas a través del desarrollo de un nuevo producto con entidad propia, además de crear campañas promocionales de relevancia. Es decir, primero se ha de a) diseñar una nueva oferta turística y, después, b) se ha de comercializar y promocionar dicha oferta.

Lo que se impone es la estrategia de la innovación constante incorporando algo nuevo que tenga éxito y que además se encuentre bien planificado, ya que en el sector del turismo intervienen cada vez más un mayor número de agentes implicados.

En el caso de Chile su localización geográfica extrema afecta el lento desarrollo de su ciclo de vida. Tal como se ha analizado en el presente artículo, definir el ciclo de vida, implica entender el potencial del mercado, y evidentemente no es esperable que Chile tenga como objetivo conseguir un turista extranjero por habitante como tiene España.

Por otra parte, no ha habido una política de comunicación consistente y un buen posiciona- miento de Chile, ya que el instrumento de comunicación, cuyo fin es dar a conocer el producto/destino en sus primeras fases del ciclo, no ha conseguido su objetivo.

Desde un plano normativo, se considera por lo tanto, que en las últimas fases del ciclo de vida la situación requiere desarrollar, por una parte, una comunicación fundamentalmente persuasiva de la oferta; sin embargo la comunicación de la nueva oferta turística, que también requiere desarrollarse en esta etapa, debe tener predominantemente un carácter informativo. Si el destino se encuentra en las primeras fases del ciclo de vida se propone desarrollar una comunicación esencialmente informativa, basada en las características del producto: recursos disponibles y sus combinaciones, además de hacer hincapié en los motivos del turista en la visita del destino. Con el objetivo de evitar generar una imagen difusa en la mente de los potenciales turistas es preciso desarrollar un posicionamiento diferenciado ligado a ejes de comunicación concretos basados en lugares emblemáticos, actividades temáticas y la cultura local.

Una vez contrastada la proposición teórica sobre las fases del ciclo de vida en la que se encuentran los destinos turísticos objeto de estudio y el análisis de las estrategias de comunicación en sus etapas se puede concluir que el estudio realizado permite utilizarse como una orientación para las entidades y destinos turísticos, sin implicar por ello una capacidad predictiva.

A pesar de la cuidadosa selección de los casos de estudio, las características de la oferta y la competencia inherentes a cada destino y su público objetivo, implican particularidades que se han demostrado fundamentales a la hora de diseñar las estrategias de comunicación. Ello supone una limitación a la hora de extrapolar las 
conclusiones exploratorias relativas a la planificación de esta herramienta en dos etapas clave del ciclo del destino, como son la etapa de desarrollo y la etapa de estancamiento, a otros destinos en las mismas fases. Por ello sería conveniente extrapolar el estudio a otros destinos en las mismas etapas con particularidades en su oferta y competencia distintas a los casos anali- zados de España y Chile. Asimismo también sería conveniente desarrollar este análisis en destinos en etapas de exploración, consolidación y declive. En esta línea, se podría proporcionar unas pautas de comunicación integrada, en la que los distintos agentes implicados podrían trabajar de forma coordinada bajo un lema común.

\section{Bibliografía}

Aguiló, E. y Alegre, J. (2005). La madurez de los destinos turísticos de sol y playa. El caso de las Islas Baleares. Papeles de Economía Española, 102, 250-271.

Aguiló, E., Alegre, J., Cladera, M. y Sard, M. (2002). La fase de postestancamiento de un destino turístico maduro. Dressing up to screen the same blowsy tart?". Investigación Turística. Premio Tribuna FITUR Jorge Vila Fradera. Madrid: Fitur. Berry, T. (2001). An Application of Butler's (1980) Tourist Area Life Cycle Theory to the Cairns Region, Australia 1876-1998, Tesis doctoral, School of Tropical Environment Studies and Geography. James Cook University of North Queensland, Queensland.

Bigné, J.E., Font, X. y Andreu, L. (2000). Marketing de destinos turísticos: Análisis y estrategias de desarrollo. Madrid: ESIC.

Butler, R. (1980). The Concept of a Tourist Area Cycle of Evolution: Implications for Management of Resources". Canadian Geographer, 24 (1), 5-12.

Butler, R. (1996). The Concept of Carrying Capacity for Tourism Destinations: Dead or Merely buried. Progress in Tourism and Hospitality Research, 2 (3-4), 283-293

Butler, R. (2001). The Resort Cycle Two Decades On. En Tourism in the 21st Century. Lessons from Experience (284289). Chichester: John Wiley \& Sons.

Camisón, C. (1998). Dirección estratégica de empresas y destinos turísticos: Balance del estado de la cuestión y propuesta de un marco integrador orientado a la competitivi- dad. En Actas del VIII Congreso Nacional de ACEDE. "Empresa y Economía Institucional" (49-85). Las Palmas de Gran Canaria.

Camisón, C. y Monfort, V. (1998). Estrategias de Reposicionamiento para Destinos Turísticos Maduros: El Caso de la Costa Blanca. Estudios Turísticos, 135, 7-28.

Chetty S. (1996). The case study method for research in small- and médium - sized firms. International small business journal, 15 (1), 73.

Christaller, W. (1964). Some Considerations of Tourism Location in Europe: The Peripheral Regions - Underdeveloped Countries - Recreation Areas. Papers in Regional Science, 12 (1), 95-105.

Cohen, E. (1972). Toward a Socioloty of International Tourism. Social Research, 39, 164-182.

Dean, J. (1950). Princing Policies for New Products". Harvard Business Review, 28 (6), 45-54.

Digance, J. (1997). Life Cycle Model. Annals of Tourism Research, 24 (2), 452-454.

Ejarque Bernet, J. (2005). Destinos turísticos de éxito. Madrid: Ediciones Pirámide.

Exceltur (2011). Informe perspectivas turísticas Exceltur, $\mathrm{n}^{\circ}$ 35. Disponible en: http://exceltur.org/excel01/contenido/ portal/files/Informe\%20Perspectivas $\% 20$ Número $\% 20$ 35\%20definitivo.pdf. Extraído el (24-4-2011). 
Foster, D.M. y Murphy, P. (1991). Resort Cycle Revisited. The Retirement Connection. Annals of Tourism Research, 18 (4), 553-567.

García Henche, B., Mielgo Álvarez, A. y Saco Vázquez, M. (2010). El desafío del sector turístico español: reposicionamiento de la oferta y retos promocionales para la adaptación a los nuevos segmentos. Actas del $11^{\circ}$ Forum Internacional sobre Las Ciencias, las Técnicas y el Arte aplicadas al Marketing. Academia y Profesión (121-142).

Gilbert, E. (1939). The Growth of the Island and Seaside Health Resort in England. Scottish Geographical Magazine, $55,16-35$.

Gonçalves, V.F y Aguas, P.M. (1997), "The Concept of Life Cycle: An Application to the Tourist Product". Journal of Travel Research, 32 (2), 12- 22.

Harrison, D. (1995). Development of Tourism in Swaziland. Annals of Tourism Research, 22 (1), 135-156.

Hovinen, G., (2002). Revisiting the Destination Lifecycle Model. Annals of Tourism Research, 19 (1), 209-230.

Instituto de Estudios Turísticos (2006). Plan de Objetivos de Promoción Exterior del Turismo. Disponible en: http:// www.tourspain.es/NR/rdonlyres/F1A39EB9-B25D-4703B271-9F9DC16483F3/8030/Memoria20099.pdf. Extraído el (18-11-2010).

Instituto de Estudios Turísticos (2010). Movimientos turísticos en Fronteras. Frontur. Disponible en: http://www.iet. tourspain.es/paginas/frontur.aspx?periodo=anual\&serie $=\mathrm{n}$ o\&seleccion=tablas\&origen $=$ menu\&idioma $=$ es ES\&option=front Extraído el (12-10-2010).

Knowles, T. y Curtis, S. (1999). The Market Viability of European Mass Tourist Destinations. A Post-Stagnation Lifecycle Analysis. International Journal of Tourism Research, 1 (2), 87-96.

Lundtorp, S. And Wanhill, S., (2001). The Resort Lifecycle Theory. Generating Processes and Estimation. Annals of Tourism Research, 28 (4), 947-964.

Martín Azami, D. (2004). Determinantes estratégicos de la fidelidad del turista en destinos maduros. Tesis doctoral, Servicio de publicaciones de la Universidad de La Laguna, La Laguna.

Maxwell, J. A. (1998). Designing a Qualitative Study. En L. Bickman D. J. y Rog (Eds.). Handbook of Applied Social Re- search Method (69-100). Thousand Oaks, CA, Sage Publications.

Medina, D.R. y García, J.M (1998). El turismo como instrumento de desarrollo: estrategias de los destinos turísticos. En Actas del VIII Congreso Nacional de ACEDE. "Empresa y Economía Institucional” (303-335). Las Palmas de Gran Canaria. Miossec, J.M. (1977). Un Modéle de LEspace Touristique. L'Espace Géographique, 6 (1) 41-48.

Moss, S.E., Ryan, C. y Wagoner, C.B. (2003). An Empirical Test of Butler's Resort Product Life Cycle: Forecasting Casino Winnings. Journal of Travel Research, 41, 393-399.

Noronha, R. (1976). Review of the Sociological Literature on Tourism. New York: World Bank.

Oreja, J.R. (2001). Evolución de destinos turísticos. En Actas del VI Congreso AECIT, I Simposium Internacional de Turismo (19-33). Ceuta.

Oreja, J.R. y Montero, I. (1997). Las estrategias de gestión del entorno en la conformación de la imagen de los destinos turísticos maduros. El caso de Puerto de la Cruz (Tenerife). En Capitale naturale e ambiente. Milano: Franco Angeli.

Plog, S.C. (1974). Why Destination Areas Rise and Fall in Popularity. The Cornell Hotel and Restaurant Administration Quarterly, 42 (3), 55-58.

Priestley, G. y Mundet, L. (1998). The Post-Stagnation Phase of the Resort Cycle. Annals of Tourism Research, 25 (1), 85-111.

Sarabia, FJ. (1999). Metodología para la investigación en marketing y dirección de empresas. Madrid: Piramide.

Secretaría General de Turismo (2008). Plan del turismo Español. Horizonte 2020. Madrid: Ministerio de Industria, Turismo y Comercio.

Sernatur. Servicio Nacional de Turismo de Chile. Estudios y Estadisticas. Disponible en:http://www.sernatur.cl/. Extraído el (22-12-2010).

Serra Cantallops, A. (2011). Marketing turístico. Madrid: Pirámide.

Stake, R. (1994). Case studies. En Denzwhytein, N. y Lincoln, Y. (Eds). Handbook of Qualitative Research (236-245). Thousand Oaks, Sage Publictions.

Stansfield, C. (1978). Atlantic City and the Resort Cycle: Background to the Legalization of Gambling. Annals of Tourism Research, 5 (2), 238-251. 
Tooman, L. (1997). Applications of the Life-Cycle Model in Tourism. Annals of Tourism Research, 24 (1), 214-234.

Vera, J.F. y Monfort, V.M. (1994). Agotamiento de modelos turísticos clásicos. Una estrategia territorial para la cualificación: La experiencia de la Comunidad Valenciana. Estudios Turísticos, 123, 17-45.
WTO Word Trade (2009). Organizacion. Intenational Trade Statistics. Disponible en: http://www.wto.org/english/res_e/ statis_e/its2009_e/its09_toc_e.htm. Extraído el (12-1-2011). Yin, R.K. (1994). Case Study Research - Design and Methods, Applied Social Research Methods (Vol. 5, 2nd Ed.). Newbury Park: Sage Publications. 